Meta

Journal des traducteurs

Translators' Journal

\title{
Basic Spanish Terminology for Translation Studies: A Proposal
}

\section{Julio César Santoyo et Rosa Rabadán}

Volume 36, numéro 1, mars 1991

La terminologie dans le monde : orientations et recherches

URI : https://id.erudit.org/iderudit/004028ar

Aller au sommaire du numéro

Éditeur(s)

Les Presses de l'Université de Montréal

ISSN

0026-0452 (imprimé)

Découvrir la revue

Citer cet article

Santoyo, J. C. \& Rabadán, R. (1991). Basic Spanish Terminology for Translation Studies: A Proposal. Meta, 36(1), 318-322.

\section{Résumé de l'article}

Récente dans le monde hispanophone, la théorie de la traduction a généré une grande quantité de livres, d'articles, de conférences, etc. Toutefois, elle souffre d'une carence terminologique. Puisqu'elle dépend des corpus lexicaux étrangers, elle prend graduellement du retard par rapport aux langues qu'elle imite, principalement le français et l'anglais. Le lexique d'appellations nouvelles proposé compte quelque soixante-dix mots-clés, accompagnés de brèves définitions en espagnol et de la traduction anglaise, lorsqu'elle existe. 


\title{
BASIC SPANISH TERMINOLOGY FOR TRANSLATION STUDIES: A PROPOSAL
}

\author{
J.C. SANTOYO AND R. RABADÁN \\ University of León, Leơn, Spain
}

RÉSUMÉ

Récente dans le monde hispanophone, la théorie de la traduction a généré une grande quantité de livres, d'articles, de conférences, etc. Toutefois, elle souffre d'une carence terminologique. Puisqu'elle dépend des corpus lexicaux étrangers, elle prend graduellement du retard par rapport aux langues qu'elle imite, principalement le français et l'anglais. Le lexique d'appellations nouvelles proposé compte quelque soixante-dix mots-clés, accompagnés de brèves définitions en espagnol et de la traduction anglaise, lorsqu'elle existe.

A recent development in the Spanish-speaking world, Translation Studies are having a considerable boom in books, articles, both national and international conferences, lectures, university courses and so on. As a young discipline, however, it lacks an adequate, generally accepted and widely used terminology (now partially different in every country), and, depending as it does on foreign lexical corpuses, lags slowly behind those very languages it imitates, mainly French and English, and, on a smaller scale, German.

Spanish scholars and researchers, most of whom have moved in from adjacent disciplines such as General Linguistics and Literary Criticism, tend to go on using the foreign models, methods and terminology specific to the field. Hence the variety of words used to refer to one and the same concept within Translation Studies.

Significantly enough, the most widely known works on the subject (Vazquez-Ayora 1977, Zierer 1979, Maison 1983, and Santoyo $1983 \& 1985$ ) make use of completely different terminologies, largely due to the various linguistic and cultural "theories" their models draw upon.

Even if the situation is one of actual confusion, there exists a good number of wellestablished terms in the Spanish literature on the subject, irrespective of the theoretical model involved, such as traducción [translation], traductor [translator], interpretación [interpretation], intérprete [interpreter], traducir [translate], interpretar [interpret], fidelidad [fidelity, faithfulness], paráfrasis [paraphrase], préstamo [loan-word], traducción interlineal [interlinear translation], crítica, análisis y evaluación de traducciones [translation quality assessment], etc. We will not deal with them, as they belong to an undisputed common lexical stock.

Ours is only a proposal, and quite a modest one, which aims at selecting and renaming about seventy key words (short definitions included) suitable for use as standard terminology in the field all over the Spanish-speaking world. Of course, the need for giving the definitions of such lexical items in Spanish is self-evident. However, the usual English form has been provided, when possible (or known), after each entry. 
The following abbreviations are used throughout: TR, traducción [translation]; LO, lengua de origen [source language]; LM, lengua meta [target language]; TO, texto de origen [source text]; TM, texto meta [target text]; PS, polisistema [polysystem].

Aceptabilidad. 'Privilegio' de las normas y reglas que derivan del PS meta en un proceso de TR: denota el grado de tolerancia y respuesta del lector ante el TM. [Acceptability]

Actuación. Manifestación textual de la competencia traductora (vide). La actuación traductora es el hecho concreto de la TR, que desemboca en un TM, individual y específico. Una competencia sin actuación es pura entelequia gramatical, abstracción linguística imposible de comprobar, más aún de ponderar. La TR no existe sino en actuación y la competencia de un traductor sólo se demuestra en sus realizaciones. [Performance]

Adaptación. Texto aparentemente traducido, cuya dependencia del TO correspondiente es escasa, o cuando menos débil, y que al no presentar una relación global de equivalencia no puede considerarse TR. En estos casos, el TO no es en sentido estricto aquél del que parte el proceso de transferencia, sino la fuente de inspiración sobre la que se construye un nuevo texto perteneciente a un PS diferente. [Adaptation]

Adecuación. Noción restrictiva, y al tiempo complementaria, de la de aceptabilidad, que supone 'privilegiar' en un proceso de TR las normas y reglas que derivan del PS de origen. [Adequacy]

Asistida (TR). Proceso de transferencia TO > TM en el que intervienen, a distintos posibles niveles, sistemas informáticos de ayuda al traductor. [Computer/machine-aided translation]

Autotraducción. TR realizada por el propio autor del TO. Ej.: la obra de Samuel Beckett. [Self-translation]

Binomio textual. Todo par TO-TM unido por una relación de equivalencia translémica, es decir, un TO y su TR. [Textual binomial]

Calco. Término o sintagma unívoco de la LM, traducido casi siempre de forma literal de un término o sintagma correspondiente de la LO para designar en la LM un concepto hasta ese momento inexistente. [Calque, loan-translation].

Competencia traductora. Capacidad activa de discernimiento

interlingüístico; 'gramática' o sistema interiorizado de relaciones interlingüísticas en el que esa capacidad y pericia encuentran expresión y que permiten al traductor generar en la LM, en condiciones de equivalencia (vide) contrastada, el mismo mensaje que contenía el TO. Menos pasiva que la unilingüe, más reflexiva y consciente (puesto que, más que saber, entraña sobre todo discernir y ponderar), la competencia traductora se muestra como una actitud empírica y despierta, solícita en la búsqueda, reconocimiento y aceptación de la consonancia interlingüística. [Competence]

Comunicativa (TR). Vide Equivalencia comunicativa.

Consecutiva (interpretación). Aquella en la que la TR oral a la LM se realiza con posterioridad a la emisión, total o fragmentaria, del mensaje oral en la LO. [Consecutive interpreting] 
Correspondencia formal. Supuesta relación de equivalencia que se establece entre categorías lingüísticas paralelas de la LO y LM, las cuales desempeñan idéntica función en sus sistemas respectivos. [Formal.correspondence]

Descodificación. Proceso que realiza el traductor para internalizar e interpretar el TO como paso previo a la transferencia propiamente dicha. [Decoding].

Directa (TR). La realizada a una LM que es al tiempo la materna del traductor.

Doblaje. Variedad de TR cinematográfica, cuyo rasgo más relevante es la sincronía entre imagenes y texto oral. [Dubbing]

Encubierta (TR). TM que disfruta de la condición de TO en el PS meta, por no estar el TO específicamente ligado a las condiciones socioculturales del PS origen. [Covert]

Equivalencia. Noción central de la disciplina translémica, de carácter dinámico y condición funcional y relacional, presente en todo binomio textual (vide) y sujeta a normas de carácter socio-histórico. Determina, con propiedad definitoria, la naturaleza misma de la TR. Calificada así como equivalencia comunicativa otranslémica. [Equivalence]

Estrategias de TR. Vide Técnicas de transferencia. [Translationstrategies]

Estudios de TR. Denominación (la más general) de este área deconocimiento, que además de las ramas básicas, incluye cuestiones de bibliografía, literatura comparada, historia de la TR, etc. [Translation Studies]

Glosa. TR puntual y marginal de elementos microtextuales. Ej.: Glosas Emilianenses, Glosas Silenses. [Gloss]

Inequivalencia. Desviación o limitación puntual en la aplicabilidad de la equivalencia (vide) en un binomio textual dado. Puede tener origen lingüístico, o bien obedecer a causas extralinguísticas. [Non-equivalence, inequivalence]

Infratraducción. Ausencia en el TM de elementos de especificación semántica patentes en el TO. [Undertranslation]

Interferencia. Sobreimposición en el TM de rasgos semánticos y/o estructurales peculiares de la LO. [Interference]

Interlingüística (TR). Reformulación de un TO mediante signos verbales de una LM. [Interlingual]

Intermedia. TM que a su vez sirve de TO para una nueva TR a un tercer idioma. [Intermediate]

Intersemiótica (TR). Reformulación o transmutación de un mensaje expresado en signos verbales por medio de un sistema de signos no verbal (Jakobson 1959). [Intersemiotic]

Intertextualidad. Interrelación explícita apreciable (por traductor y lector) que un TM manifiesta respecto a la tradición textual del PS de origen. [Intertextuality]

Intraducibilidad. Noción prescriptiva según la cual determinados segmentos textuales de la LO resultan intransferibles a un segundo código lingüístico por no existir en la LM resoluciones de correspondencia aceptables para el receptor meta. Llevada a sus últimas consecuencias, derivaría en la imposibilidad de la TR, sostenida históricamente por algunos teóricos. [Untranslatability]

Intralingüística (TR). Reformulación, generalmente por razones de diacronía lingüística, de un TO mediante otros signos verbales de la misma LO (Jakobson 1959). [Intralingual] Inversa (TR). La realizada a una LM que no es la materna del traductor. 
Lector. Criterio último que determina la aceptabilidad (vide) del TM en el PS meta. Sinónimo: receptor, destinatario. [Reader, audience, receptor.]

Lengua meta (LM). Código linguístico utilizado en el texto meta (TM). [Target language]

Libre (TR). Procedimiento de transferencia (y su producto textual) que reproduce el contenido del TO en el TM utilizando una forma básicamente distinta. [Free translation]

Literal (TR). Procedimiento de transferencia (y su producto textual) que convierte las construcciones gramaticales de la LO en sus correspondencias formales más cercanas en la. LM. [Literal translation]

LM. Lengua meta. [TL, target language]

LO. Lengua de origen. [SL, source language]

Meta. Alude a la lengua y texto de la TR. [Target]

Metatraducción. Operación de condición semiológica que recrea en el TM cualquier función metalingüística presente en el TO, haciendo uso de procedimientos lingüísticos equiparables, caso que las reglas de la LM lo permitan. [Metatranslation]

Microtexto. Texto breve y autónomo, o fragmento textual con sentido propio, con frecuencia desligado de un más amplio co-texto y contexto.

Origen. Texto (de) origen (TO), lengua (de) origen (LO). [Source]

Patente (TR). TM que no disfruta de la condición de TO en el PS meta, por estar el TO específicamente ligado a las condiciones socio-culturales del PS de origen. [Overt]

Polisistema. Conjunto de co-sistemas semióticos interrelacionados de forma dinámica y regulados por normas históricas, en el que se inscriben todas las actividades behaviorísticas y sociales del ser humano, incluida la propia TR. [Polysystem]

Protolector. El traductor como lector 'especial' del TO: su lectura y personal interpretación del mismo determinan en última instancia el resultado final del proceso de TR, es decir, el TM.

Receptor. Vide Lector.

Recodificación. Reformulación textual del TO en la LM. [Encoding]

Relaciones translémicas. Aquellas que se establecen entre TM y TO bajo el postulado de equivalencia (vide) y que dependen de las normas de comportamiento traductor y reglas sistémicas del PS meta.

Retraducción. Operación de transferencia, donde el 'input' del proceso es el 'output' de una operación anterior de transferencia en dirección inversa, es decir, una re-versión a la LO del TO ya traducido. [Back-translation]

Seudotraducción. Forma de ficción literaria mediante la cual un autor 'oculta' su propio TO so capa de TM. Ej.: Don Quijote, Lettres persanes, Il nome della rosa. [Pseudotranslation]

Simultánea (interpretación). Aquella en la que la TR oral a la LM se realiza de forma cuasi simultánea a la emisión oral del mensaje en la LO. [Simultaneous interpreting]

Sobretraducción. Presencia en el TM de elementos de especificación semántica no patentes en el TO. [Overtranslation]

Subordinada (TR). Toda modalidad de transferencia interpolisistémica donde intervengan medios vehiculares en los que un TO esté imbricado (cine, canción, cómics, etc.). [Constrained translation] 
Subtitulado, subtítulos. Variedad de TR cinematográfica, cuyo rasgo más relevante es la sincronía espacio-tiempo entre TO oral y TM sobreimpreso a pie de imagen. [Subtitling, subtitles]

Técnicas de transferencia. Procedimientos y recursos lingüístico-textuales usados para reformular el TO según las posibilidades del PS meta y reducir al mínimo las zonas de inequivalencia que derivan de la ausencia de isomorfismo entre dos polisistemas. Incluyen: adaptación [adaptation], compensación [compensation], modulación [modulation], concentration [concentration], transposición [transposition], etc. [Translation techniques]

Tipo textual. En los Estudios de TR, conjunto de parámetros discursivos en los que se inscribe todo TO susceptible de TR y que predetermina ciertos aspectos del proceso de transferencia. Los criterios de clasificación tipológica difieren notablemente según los autores.

TM. Texto meta. [TT, target text]

TO. Texto de origen. [ST, source text]

Traducibilidad. Noción prescriptiva que indica el nivel potencial de trasvase lingüísticotextual de un sistema LO a otro LM en virtud de la relaciones intersistémicas de ambos. El concepto de traducibilidad total derivaría del postulado de los universales lingüísticos. [Translatability]

Traductología. Rama de la Lingüística Aplicada que hace uso de los principios y métodos de ésta para describir los fenómenos del proceso traductor. [Traductology]

Transferencia. Proceso de trasvase y reformulación interlinguísticos. [Transference]

Translema. Unidad bitextual de cualquier tipo o nivel constituida por un mismo contenido y dos manifestaciones formales diferenciadas pero solidarias y cuya existencia depende de la relación global de equivalencia subyacente a cada binomio textual TO-TM. [Transleme]

Translémica. Disciplina que se ocupa, en un marco abstracto y metodológico propio, de explicar, predecir y dar cobertura teórica sistemática, a la vez que coherente, a los fenómenos y procesos de TR. Su noción central es la 'equivalencia translémica' (vide) y su unidad el translema (vide). [Translemics]

Transliteración. Sustitución de las unidades grafémicas de la LO por otras equivalentes de la LM. [Translateration]

Transposición escénica. Puesta en escena de un TM dramático, mediante la cual la página escrita se realiza finalmente como teatro.

Unidad de TR. Vide translema.

Vacío semántico. Carencia semántica que se observa en la comparación interlinguíística y que deriva de las diferentes reglas de selección y acumulación semántica de la LO y LM. [Semantic void]

Versión. Sinómino de traducción. En TR teatral, la realizada con miras primordialmente escénicas. 